\title{
Анизотропия термоэдс в высших силицидах переходных металлов
}

\author{
(C) В.С. Кузнецова ${ }^{1,2}$, В.К. Зайцев ${ }^{1}$, Ф.Ю. Соломкин ${ }^{1}$, С.В. Новиков ${ }^{1}$ \\ ${ }^{1}$ Физико-технический институт им. А.Ф. Иоффре Российской академии наук, \\ 194021 Санкт-Петербург, Россия, \\ ${ }^{2}$ Академический университет Российской академии наук, \\ 194021 Санкт-Петербург, Россия \\ E-mail: vicha_110901@mail.ru
}

(Получена 31 января 2017 г. Принята к печати 8 февраля 2017 г.)

\begin{abstract}
Применена новая методика измерения анизотропии термоэдс с использованием поликристаллов, основанная на многократном измерении ансамбля микрокристаллов при их случайной ориентации и статистической обработке результатов измерений. С использованием поликристаллов измерена анизотропия термоэдс ряда высших силицидов переходных металлов ( $\beta-\mathrm{FeSi}_{2}$, легированного $\left.\mathrm{MnSi}_{1.75}, \mathrm{ReSi}_{1.75}, \mathrm{CrSi}_{2}\right)$. В кристаллах $\beta-\mathrm{FeSi}_{2}$ может возникать очень большая величина анизотропии термоэдс, в кристаллах $\mathrm{ReSi}_{1.75}$ возможна термоэдс различного знака, в $\mathrm{CrSi}_{2}$ установлена сильная зависимость абсолютной величины термоэдс и ее анизотропии от температурных режимов термообработки. Измерены температурные зависимости электропроводности и термоэдс иголок $\mathrm{CrSi}_{2}$. Анизотропия термоэдс в них, так же как и в объемных монокристаллах, сохраняется в широком интервале температур.
\end{abstract}

DOI: 10.21883/FTP.2017.08.44775.44

\section{1. Введение}

Термоэлектрические преобразователи тепловой энергии в электрическую находят все большее применение в практике. Известно, что существует два основных типа термоэлектрических преобразователей [1]. Первый тип - классический термоэлемент. Он состоит из двух ветвей $p$ - и $n$-типа, соединенных между собой. При этом эдс определяется по формуле $V=\left(S_{p}-S_{n}\right)\left(T_{r}-T_{x}\right)$. Именно этот тип термоэлемента используется в большинстве термоэлектрических генераторов и термоэлектрических охлаждающих устройствах, основанных на обратном эффекте (эффекте Пельтье). Слабым звеном этого типа термоэлементов является коммутация ветвей по горячей стороне и необходимость их согласования по коэффициентам теплового расширения.

Вторым типом термоэлектрических преобразователей тепловой энергии в электрическую является анизотропный термоэлемент. В этом типе термоэлементов используется эдс, возникающая перпендикулярно тепловому потоку из-за анизотропии термоэдс. В настоящей работе представлены результаты исследования термоэдс четыpex соединений: высшего силицида марганца $\mathrm{MnSi}_{1.75}$ (тетрагональная кристаллическая решетка), $\beta-\mathrm{FeSi}_{2}$ (орторомбическая структура), $\mathrm{ReSi}_{1.75}$ (моноклинная структура) и $\mathrm{CrSi}_{2}$ (гексагональная структура). Тензор термоэдс кристаллов тетрагональной и гексагональной симметрии имеет две независимые компоненты. Мы обозначим их $S_{1}$ и $S_{2}$ : первая соответствует направлению теплового потока вдоль гексагональной или тетрагональной оси кристалла (далее - ось $C$ ), вторая - потоку тепла в перпендикулярном этой оси направлении. У кристаллов орторомбической симметрии тензор термоэдс может иметь 3 независимых компонента, соответствующих потокам тепла вдоль осей $A, B$ и $C$. А у кристаллов моноклинной симметрии тензор термоэдс помимо трех диагональных компонентов может иметь два недиагональных компонента, связывающих поток тепла вдоль одной из осей кристалла и электрическое поле, возникающее вдоль другой оси. Однако моноклинная решетка $\mathrm{ReSi}_{1.75}$ представляет собой слегка деформированную тетрагональную структуру (искажение $<1 \%$ ), поэтому в первом приближении можно считать, что тензор термоэдс $\mathrm{ReSi}_{1.75}$ также имеет только 2 компонента. Орторомбическая структура $\beta$-FeSi 2 также может рассматриваться как слегка искаженная тетрагональная, с двумя компонентами тензора термоэдс.

Когда тепловой поток направлен под некоторым углом $(\alpha)$ к оси $C$ кристалла, тогда эдс $\left(V_{a}\right)$, возникающая на длине $L$ вдоль направления, перпендикулярного направлению теплового потока, определяется выражением [1]:

$$
V_{a}=\Delta S \Delta T \frac{L}{d} \sin \alpha \cos \alpha,
$$

где $\Delta S=S_{1}-S_{2}, \Delta T-$ разность температур, $d-$ толщина термоэлемента. В этом случае наиболее важным параметром является $\Delta S$, т. е. величина анизотропии термоэдс и геометрия термоэлемента. Преимущества анизотропных преобразователей: отсутствие электрического контакта (коммутации) по горячей стороне, возможность управлять выходными параметрами за счет оптимизации геометрии термоэлемента, отсутствие необходимости согласования теплового расширения ветвей термоэлемента. К недостаткам метода относится сравнительно невысокая эффективность известных анизотропных термоэлектриков.

В настоящее время известно лишь очень небольшое количество кристаллов с высокой анизотропией термоэдс. В значительной степени это связано с тем, что для исследования анизотропии термоэдс использовались массивные монокристаллы, получение которых из-за особенностей диаграммы состояния или высокой температуры плавления было затруднительно, и требовались 
Некоторые свойства высших силицидов переходных металлов

\begin{tabular}{c|c|c|c}
\hline Состав & $T_{\text {пл }}, \mathrm{K}$ & $\begin{array}{c}\text { Кристаллическая } \\
\text { решетка }\end{array}$ & $E_{g}, \mathrm{eV}$ \\
\hline $\mathrm{MnSi}_{1.75}$ & 1430 & Тетрагональная & 0.66 \\
$\mathrm{CrSi}_{2}$ & 1763 & Гексагональная & 0.34 \\
$\beta-\mathrm{FeSi}_{2}$ & 1490 & $\begin{array}{c}\text { Орторомбическая } \\
\text { Моноклинная }\end{array}$ & 0.87 \\
$\mathrm{ReSi}_{1.75}$ & 2213 & $\begin{array}{c}\text { ( орторомбическая }) \\
\alpha=89^{\circ} 9^{\prime}\end{array}$ & 0.16 \\
& &
\end{tabular}

веские основания для разработки технологии их получения. Поэтому весьма актуальной является разработка экспрессного метода изучения анизотропии термоэдс без использования массивных монокристаллов, который бы позволял исследовать влияние на анизотропию термоэдс состава и технологических факторов. Весьма перспективными анизотропными термоэлектриками являются высшие силициды переходных металлов, анизотропия термоэдс которых исследована недостаточно [2].

Целью настоящей работы являлись развитие новой методики экспрессного измерения анизотропии термоэдс с использованием поликристаллов, основанной на многократном измерении ансамбля микрокристаллов при их случайной ориентации, статистическая обработка результатов измерений и проведение комплекса исследований анизотропии термоэдс полупроводниковых высших силицидов переходных металлов $\mathrm{MnSi}_{1.71-1.75}$, $\mathrm{CrSi}_{2}, \mathrm{FeSi}_{2}, \mathrm{ReSi}_{1.75}$. Некоторые свойства этих соединений представлены в таблице. Все эти соединения обладают высокой температурой плавления и являются полупроводниками.

\section{2. Методика эксперимента}

Поликристаллические образцы исследуемых материалов получены методом прямого сплавления компонентов. Состав контролировали рентгенофазовым анализом. В дальнейшем эти образцы измельчали и для измерений отбирали монокристаллические микрокристаллики. Образцы $\mathrm{ReSi}_{1.75}$ получены высокочастотным нагревом методом бестигельной плавки [3]. Измерения термоэдс проводили на установке, состоящей из холодильника, нагревателя и термопар. Образец зажимали между холодильником и нагревателем, напряжение и температуру считывали с термопар. Теоретические зависимости статистического распределения термоэдс на ансамбле микрокристаллов исследованы в работе [4]. При этом было получено два типа зависимостей. Для микрокристаллов с выделенным направлением характерна „двугорбая“ зависимость, а при отсутствии выделенного направления - монотонная зависимость без особенностей.

С целью апробации методики исследования на поликристаллах анизотропия термоэдс в высшем силициде марганца была исследована на монокристаллическом образце. После этого монокристалл измельчали, и анизотропию исследовали на ансамбле микрокристаллов. Максимумы распределения термоэдс на ансамбле микрокристаллов совпадают с термоэдс по главным направлениям монокристалла [5].

\section{3. Экспериментальные результаты}

По разработанной методике была исследована анизотропия термоэдс ряда высших силицидов переходных металлов. При больших концентрациях примесей сложно получить хороший кристалл, тогда как при помощи примесей можно оптимизировать его свойства. Исследована анизотропия термоэдс легированного $\mathrm{MnSi}_{1.75}$ (рис. 1). Видно, что в легированных образцах $\mathrm{MnSi}_{1.75}$

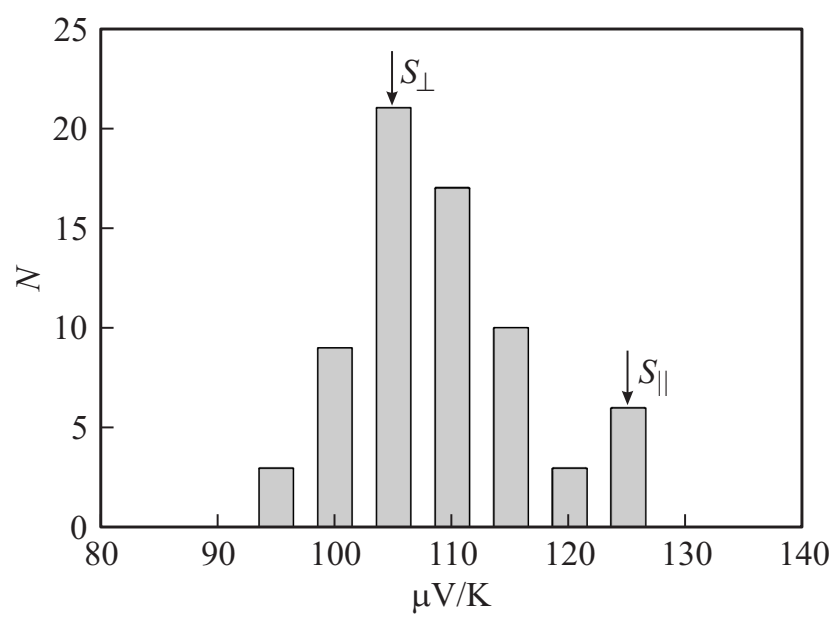

Рис. 1. Термоэдс легированного молибденом и германием высшего силицида марганца $\left(\mathrm{Mn}_{0.99} \mathrm{Mo}_{0.01}\right)\left(\mathrm{Si}_{0.99} \mathrm{Ge}_{0.01}\right)_{1,75}$. Стрелками обозначены наиболее вероятные значения термоэдс вдоль $\left(S_{\|}\right)$и перпендикулярно $\left(S_{\perp}\right)$ тетрагональной оси $C$, $N-$ количество измерений.

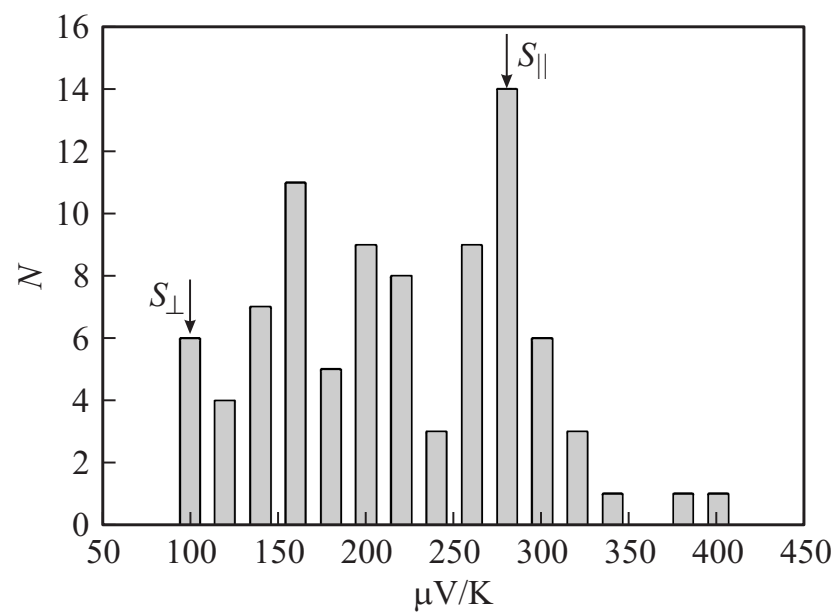

Рис. 2. Термоэдс ансамбля микрокристаллов низкотемпературной фазы дисилицида железа $\beta$-FeSi 2 . Стрелками обозначены наиболее вероятные значения термоэдс по главным осям кристалла, $N-$ количество измерений. 
анизотропия термоэдс сохраняется, хотя и уменьшается по абсолютной величине.

Дисилицид железа $\mathrm{FeSi}_{2}$ претерпевает фазовый переход при $T=982^{\circ} \mathrm{C}[6]$. При кристаллизации из расплава при этом получается высокотемпературная фаза дисилицида железа, которая обладает металлическими свойствами и не представляет интереса для термоэлектричества. При попытке перевести ее в низкотемпературную фазу из-за большого изменения объема кристаллы растрескиваются. По этой причине анизотропия низкотемпературной фазы до настоящего времени исследована недостаточно. В настоящей работе впервые с использованием поликристаллов исследована анизо-

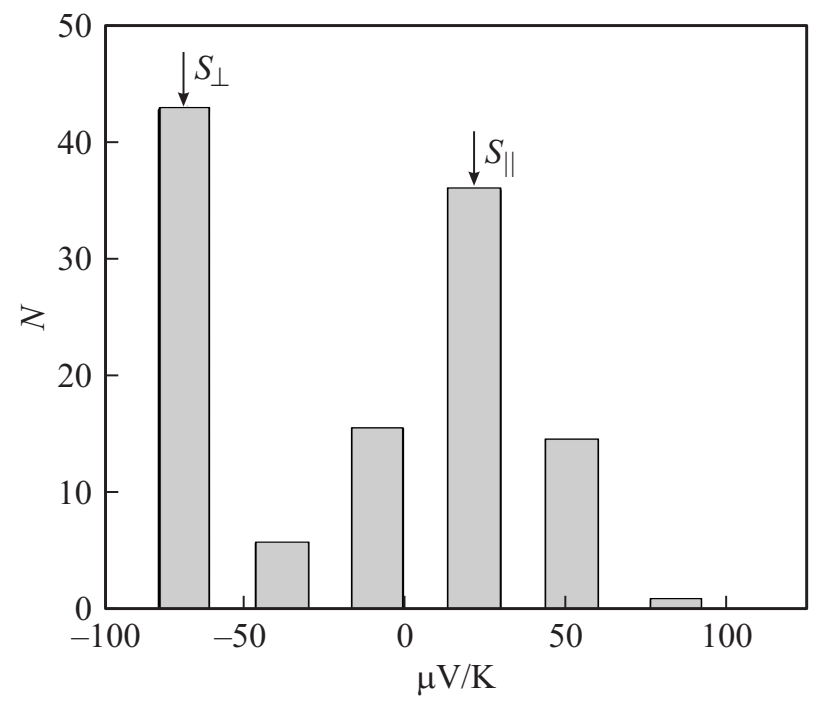

Рис. 3. Распределение термоэдс в микрокристаллах $\mathrm{ReSi}_{1.75}$. $N$ - количество измерений.

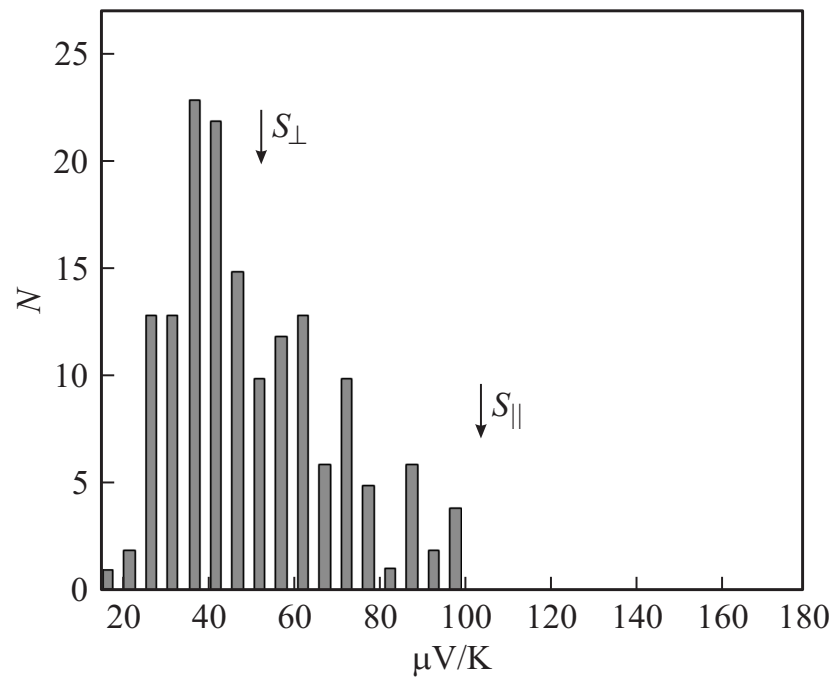

Pис. 4. Зависимость анизотропии термоэдс $\mathrm{CrSi}_{2}$ от температурных режимов охлаждения. Охлаждение в течение 40 ч. Отжиг 170 ч при $1273 \mathrm{~K} . S_{\perp}, S_{\|}-$значения термоэдс по главным кристаллическим осям массивного кристалла $\mathrm{CrSi}_{2}$, выращенного по методу Чохральского.

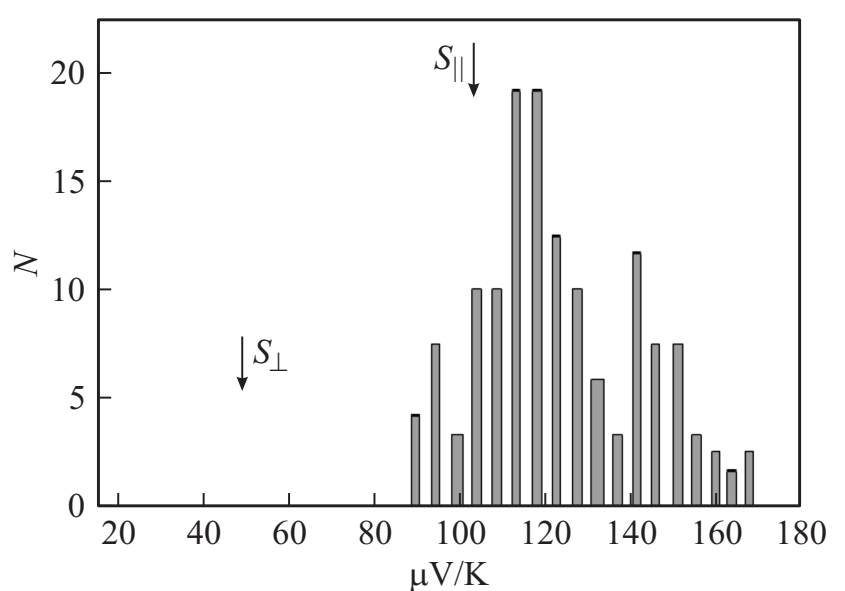

Рис. 5. Зависимость анизотропии термоэдс $\mathrm{CrSi}_{2}$ от температурных режимов охлаждения. Охлаждение 0.5 ч. Отжиг 170 ч при $1273 \mathrm{~K} . S_{\perp}, S_{\|}-$значения термоэдс по главным кристаллическим осям массивного кристалла $\mathrm{CrSi}_{2}$, выращенного по методу Чохральского.

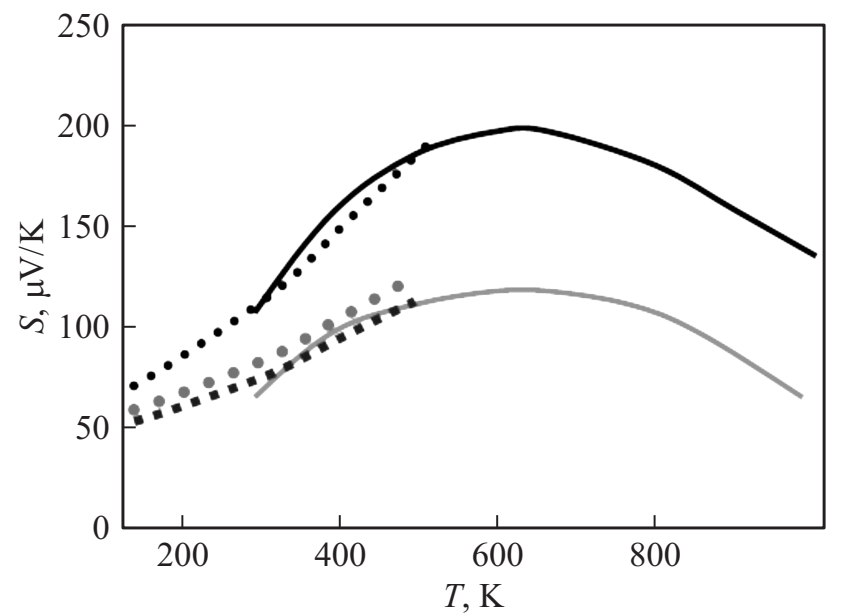

Рис. 6. Температурные зависимости термоэдс микроиголок $\mathrm{CrSi}_{2}$ - прерывистые линии. Сплошные линии - термоэдс по главным осям массивного кристалла [8].

тропия термоэдс низкотемпературной фазы дисилицида железа (рис. 2). Впервые показано, что анизотропия термоэдс полупроводниковой фазы дисилицида железа может достигать больших значений (> 150 мкВ/К).

Особый интерес вызывает исследование анизотропии термоэдс в $\mathrm{ReSi}_{1,75}$, где наблюдается термоэдс различного знака при различных ориентациях образца (рис. 3).

Диаграмма состояния $\mathrm{CrSi}_{2}$ характеризуется сильной изогнутостью в области гомогенности [6]. Поэтому можно ожидать заметного влияния режимов термообработки на кинетические свойства и анизотропию термоэдс этого соединения. Из рис. 4, 5 видно, что анизотропия термоэдс $\mathrm{CrSi}_{2}$ сильно зависит от температурных режимов термообработки. Таким образом, мы можем регулировать значения термоэдс и ее анизотропии, изменяя режимы термообработки образцов. Проведено исследование 
анизотропии термоэдс $\mathrm{CrSi}_{2}$, полученного при температуре ниже температуры плавления. С этой целью исследовалана термоэдс микроиголок $\mathrm{CrSi}_{2}$, полученных кристаллизацией из раствора-расплава $\mathrm{CrSi}_{2}$ в олове [7]. На рис. 6 сплошными линиями показана термоэдс по главным осям кристаллов $\mathrm{CrSi}_{2}$, полученных по методу Чохральского [8], точками показаны эти же величины для иголок $\mathrm{CrSi}_{2}$. Видно, что значения термоэдс, полученные на иголках, ложатся в область, ограниченную значениями для монокристалла.

\section{4. Заключение}

С использованием поликристаллов изучена анизотропия термоэдс в полупроводниковых высших силицидах переходных металлов. В кристаллах полупроводниковой фазы дисилицида железа $\beta-\mathrm{FeSi}_{2}$ может возникать очень большая величина анизотропии термоэдс $\left(\Delta S=150-200\right.$ мкв/K), в кристаллах $\mathrm{ReSi}_{1,75}$ возможна термоэдс различного знака в зависимости от кристаллографической ориентации образца, в $\mathrm{CrSi}_{2}$ установлена сильная зависимость термоэдс и ее анизотропии от температурных режимов обработки. Анизотропия термоэдс иголок $\mathrm{CrSi}_{2}$ сохраняется в широком диапазоне температур и совпадает с аналогичной зависимостью объемных образцов.

Проведенный комплекс исследований анизотропии термоэдс в высших силицидах переходных металлов может служить основой для дальнейших исследований и оптимального выбора материала для анизотропных преобразователей тепловой энергии в электрическую.

\section{Список литературы}

[1] Л.И. Анатычук. Термоэлектрики и термоэлектрические устройства (Киев, Наук. думка, 1979).

[2] M.I. Fedorov, V.K. Zaitsev. In: Medules, Systems and Applications in Thermoelectrics, ed. by D.M. Rowe (Boca Raton-London-N. Y., CRC press, 2012) p. 11-1.

[3] В.К. Зайцев, М.И. Федоров, И.В. Коркин, Б.Т. Мелех, А.А. Андреев, В.С. Петрова. В сб.: Термоэлектрики $u$ их применения. Докл. ХІІ Межсгос. семинара, под ред. М.И. Федорова, Л.Н. Лукьянова (СПб., 2010) с. 257.

[4] Зайцев В.К., Андреев А.А., Иванов Ю.В., Федоров М.И. В сб.: Термоэлектрики и их применение. Докл. ХI Межггос. семинара, под ред. М.В. Ведерникова, Л.Н. Лукьянова (СПб., 2008) с. 226.

[5] A.A. Andreev, M.I. Fedorov, Yu.V. Ivanov, V.S. Petrova, V.K. Zaitsev. J. Electron. Mater., 40 (7), 1485 (2011).

[6] П.В. Гельд, Ф.А. Сидоренко. Силициды переходных металлов четвертого периода (М., Металлургия, 1971).

[7] Ф.Ю. Соломкин, В.К. Зайцев, Н.Ф. Картенко, А.С. Колосова. В сб.: Термоэлектрики и их применение. Докл. ХІ Межсгос. семинара, под ред. М.В. Ведерникова, Л.Н. Лукьянова (СПб., 2008) с. 257

[8] В.К. Воронов, Л.Д. Дудкин, Н.Н. Трусова. Химическая связь в полупроводниках (Минск, Наука и техника, 1969).

\section{Thermopower anisotropy of transition metals silicides}

\author{
V.S. Kusnetsova ${ }^{1,2}$, V.K. Zaitsev ${ }^{1}$, F.Yu. Solomkin ${ }^{1}$, \\ S.V. Novikov ${ }^{1}$ \\ ${ }^{1}$ loffe Institute, \\ 194021 St. Petersburg Russia \\ 2 Saint Petersburg Academic University, \\ 194021 St. Petersburg, Russia
}

\begin{abstract}
A new method was applied for measurement of thermopower anisotropy. The method is based on the measurement of thermopower of an array of microcrystals with a random orientation and statistical analysis of the data.

The anisotropy of thermopower was measured for higher silicides of transition metals $\left(\beta-\mathrm{FeSi}_{2}\right.$, doped $\mathrm{MnSi}_{1.75}, \mathrm{ReSi}_{1.75}$, $\mathrm{CrSi}_{2}$ ). It was found, that a large anisotropy of thermopower appeared in $\beta$ - $\mathrm{FeSi}_{2}$ crystals, $\mathrm{ReSi}_{1.75}$ crystals had thermopower with different signs, $\mathrm{CrSi}_{2}$ crystals had strong dependences of the absolute thermopower value and anisotropy on the heat treatment mode. Temperature dependences of resistance and thermopower of $\mathrm{CrSi}_{2}$ single crystal needles, prepared by crystallization from melt solution was measured from 100 to $500 \mathrm{~K}$.
\end{abstract}

